Proceedings of the Institution of
Civil Engineers
Transport 158
February 2005 Issue TRI
Pages 53-59
Paper 13402
Received: 19/07/2004
Accepted: 09/08/2004
Keywords:
traffic engineering/transport
management/transport planning
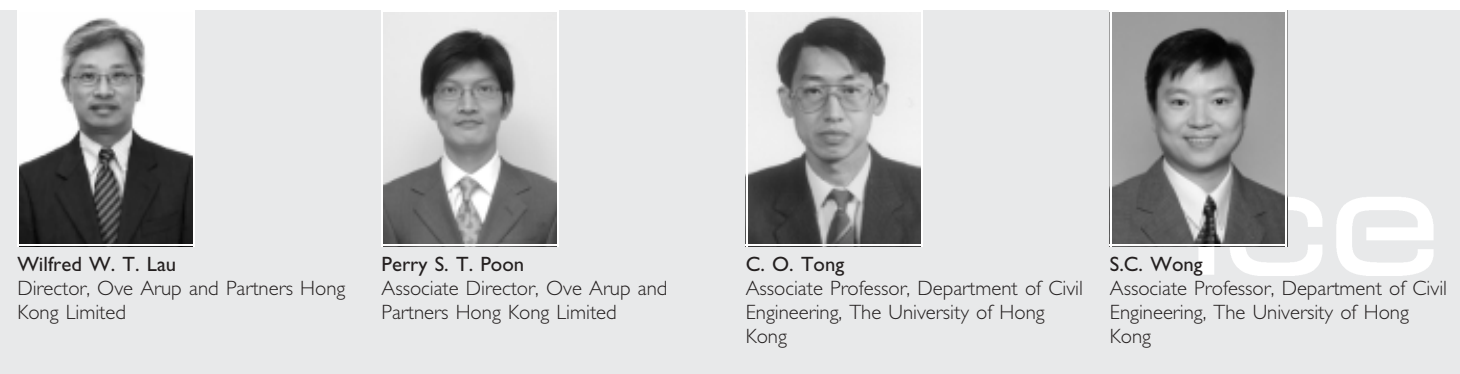

\title{
The Hong Kong second parking demand study
}

W. W. T. Lau BSc, MICE, MHKIE, RPE, PE, P. S. T. Poon BSc, MSocSc, MCIT, MIEAust, C. O. Tong BSc (Eng), PhD, MICE, FHKSTS, MHKIE and S. C. Wong MPhil, PhD, FCILT, FHKSTS, MIHT, MITE MASCE

This paper describes the background, objectives, surveys, models, findings and recommendations of the Hong Kong second parking demand study. This study aims to give strategic directions to guide the planning and management of parking facilities in Hong Kong. It comprises extensive surveys to determine the parking inventory, parking characteristics and driver behaviour. Demand models were developed to predict the future night-time and daytime parking demand over a planning horizon of 15 years. All types of vehicle, including private cars, taxis, motorcycles, coaches and goods vehicles, were included in the analysis. The recommendations of a previous parking demand study have been reviewed, and new recommendations are given.

\section{INTRODUCTION}

The city of Hong Kong has a small land area of approximately $1100 \mathrm{~km}^{2}$. Its topography is hilly, and contains many islands. With a population that is approaching 7 million, and with urban development that is concentrated in around $16 \%$ of the land area, it has residential densities that are among the highest in the world. ${ }^{1,2}$ With such a high-density development, 'land' is a scarce resource in Hong Kong. The demand for and pricing of parking spaces are also among the highest in the world. After completing the First Parking Demand Study (PDS1) in 1995 , $^{3}$ the Hong Kong Special Administrative Region (HKSAR) Government commissioned the Second Parking Demand Study (PDS-2), to be carried out during the two and a half years from 2000 to $2002 .{ }^{4}$ This paper describes the background, objectives, surveys, models, findings and recommendations of PDS-2.

\section{BACKGROUND}

Both PDS-1 and PDS-2 were strategic parking demand studies aimed at identifying present and future parking problems for Hong Kong and formulating remedial measures to address these problems. The scope of PDS-1 included conducting surveys to determine parking inventory, parking characteristics, parking behaviour and preferences, and developing models to predict daytime and nighttime parking demand. PDS-1 found a shortfall of parking spaces for all types of vehicle in most districts, particularly for goods vehicles, and recommended improvements through

(a) improving planning standards (b) optimising the use of existing facilities

(c) managing parking demand

(d) providing additional parking facilities.

In order to update the assumptions and predictions of PDS-1, the Transport Department (TD) of the HKSAR Government commissioned Ove Arup and Partners Hong Kong Ltd to undertake PDS-2.

\section{STUDY OBJECTIVES}

PDS-2 aimed to give strategic directions to guide the planning and management of parking facilities in Hong Kong. Its main objectives were

(a) to enhance the inventory of parking and loading/unloading facilities, and to convert it into a spatial format

(b) to update and recalibrate the Parking Demand Model ${ }^{5}$ developed in PDS-1

(c) to assess the present and future parking demand and supply situations

(d) to review planning standards and guidelines governing the provision of parking and loading/unloading facilities in new land-use developments

(e) to review the scale and nature of current parking-related problems

( $f$ ) to review the PDS-1 recommendations, recommend new remedial measures and formulate new initiatives.

\section{PARKING INVENTORY}

The parking inventory established in PSD-1 was a relational database that recorded the location and type of parking facilities down to building level for off-street spaces, and down to street block level for on-street spaces. Although it had since been updated regularly by TD's in-house staff, surveys were carried out in PDS-2 to validate and enrich this database and to convert it into an open GIS format, which made it compatible with the data structure of the Government's future Transport Information System (TIS). A software system called Geographic Information System for Parking (GIS-P) was developed for spatial analysis and result visualisation of parking supply.

\section{PARKING CHARACTERISTICS SURVEY}

The capacity analysis of car parks is complicated for a number of reasons. First, as for highways, the demand pattern varies 
throughout the day. Second, although the static capacity of a car park is fixed by the number of parking spaces available, the effective capacity is variable, and dependent on the parking duration of cars parked. Thus various factors that influence the time-dependent parking demand pattern and parking duration and their relationships have to be investigated, and the parking characteristics survey must also take into account the timedependent nature of parking characteristics. Finally, vehicles usually require two types of parking facilities: daytime and night-time.

For clarity of describing various techniques used in the survey and demand model, some special terms are introduced and explained in the three paragraphs below.

The accumulation of a parking facility is the number of vehicles inside the facility at a given time. An accumulation profile shows the dynamic variation of accumulation of a parking facility.

The turnover is the number of vehicles that have used the parking facility during a day. The unit accumulation factor is the accumulation divided by the turnover. A unit graph shows the dynamic variation of unit accumulation factor of a parking facility.

A daytime parking facility is a facility used for parking a vehicle at the end of a trip made for a particular activity, such as going to work, school, shop, recreation or a place of business. A night-time parking facility is a facility for parking a vehicle when the vehicle is not engaged for any particular purpose.

The objectives of the survey are to collect data to

(a) determine the aggregate accumulation profiles of off-street daytime parking facilities and on-street parking facilities in different districts in Hong Kong

(b) check the temporal stability of the unit graphs developed in PDS-1.

The survey was conducted during the months of October and November in the year 2000. The year 2000 parking inventories for off-street and on-street car parks were used as the sampling frame for the survey. After removing night-time-related car parks, a total of 3977 car parks was extracted from the offstreet inventory. The total number of parking spaces extracted is 220748 . The on-street inventory contains 16042 metered and 13688 non-metered spaces. Approximately 440 car park sites were surveyed. ${ }^{6}$

\section{I. Accumulation profiles}

To determine the accumulation profiles of individual car parks, it is necessary to collect hourly data on parking accumulation during the daytime period from 7:30 am to 10:30 pm. Data were collected by sending questionnaires to car park operators and by direct observation. The profiles were then aggregated and expanded to produce aggregate accumulation profiles for different districts in Hong Kong. In order to use the data more effectively, a cluster analysis method was used to group car parks with a similar normalised accumulation profile. ${ }^{6}$ By this method, the whole accumulation profile of a car park can be projected from an observation of the accumulation at one specific point in time.

\subsection{Unit graphs}

The unit graph concept encompasses both the accumulation profile and the turnover of a car park into a single graph, and is used to represent the effective capacity of a car park. In PDS-1, surveys were conducted to determine the unit graphs of car parks serving different land use developments. For private cars, a cluster analysis shows that unit graphs can be grouped based on the following land use types:
(a) office
(b) industrial
(c) retail
(d) community services (separately for three districts in Hong Kong: Hong Kong Island, Kowloon, and the New Territories)
(e) tertiary education
( $f)$ public utilities.

For other vehicle types, separate unit graphs were developed. In PDS-2, additional surveys were conducted for the construction of another set of unit graphs. A sensitivity analysis shows that there is no significant difference between the two sets of unit graphs. Some typical unit graphs developed in this study are shown in Figs 1 and 2.

\section{STATED PREFERENCE SURVEY}

A conjoint analysis survey was conducted to determine the relative importance of the following three factors relating to car park choice:
(a) search/wait time
(b) walk time
(c) parking fee.

Three levels were set for each of the above three attributes. An orthogonal design with nine different parking alternatives was generated. The survey was conducted at four different vehicle licence offices when vehicle owners were queuing to renew their annual vehicle licences. The sampling method used was to approach every fifth person in the queue. Out of 901 approaches, 620 respondents completed the interview, representing a response rate of $68 \cdot 8 \%$. Respondents were asked to rank the nine parking options in order of preference. The survey results were segmented according to three vehicle types:
(a) private cars
(b) light goods vehicles
(c) medium/heavy goods vehicles

and five destination land uses:
(a) shopping
(b) industrial
(c) residential
(d) office
(e) recreation.

The survey results were analysed to determine the relative importance of the three factors considered to affect car park 


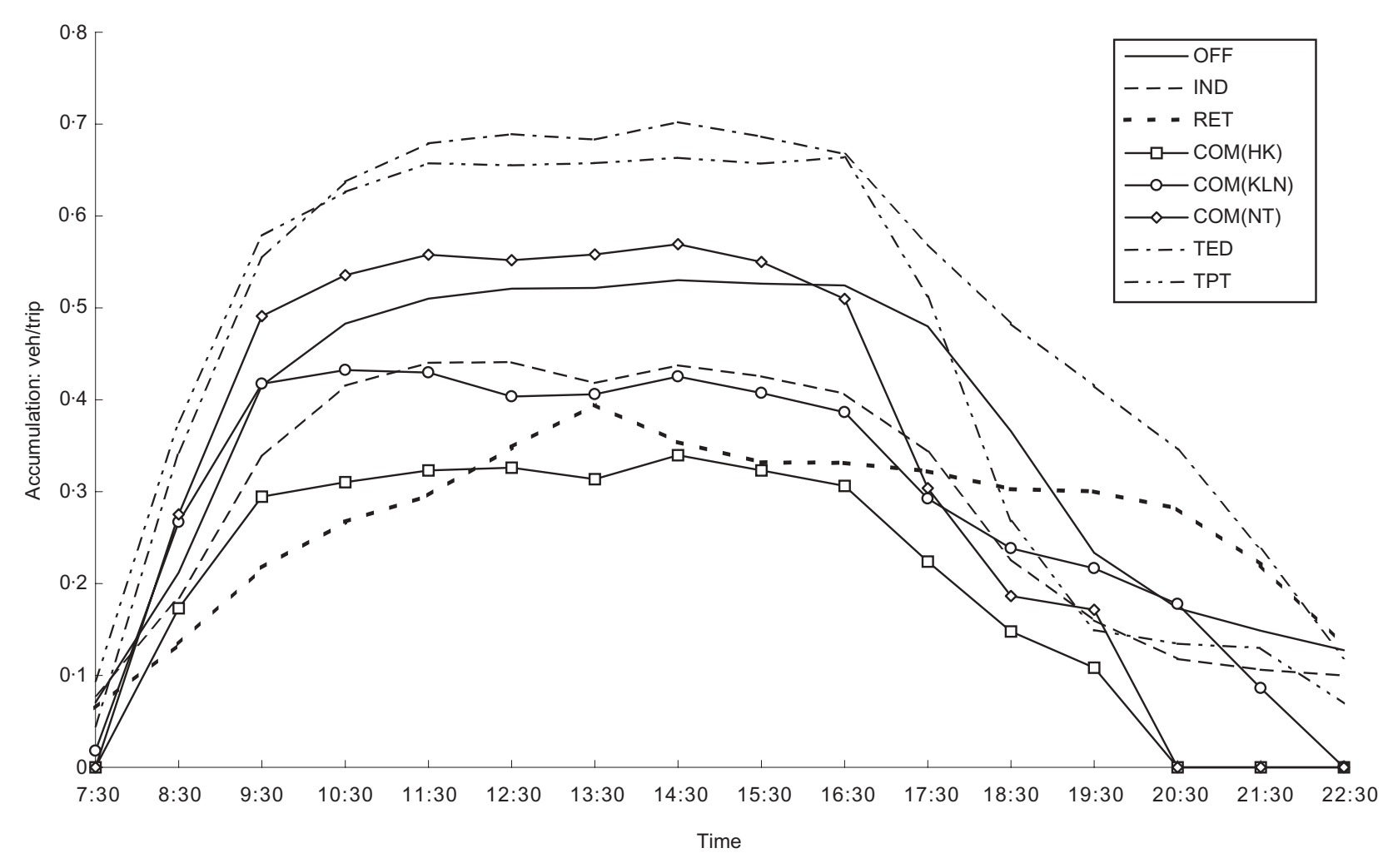

Fig. I. Typical unit graphs developed for car parks serving private cars and different land uses

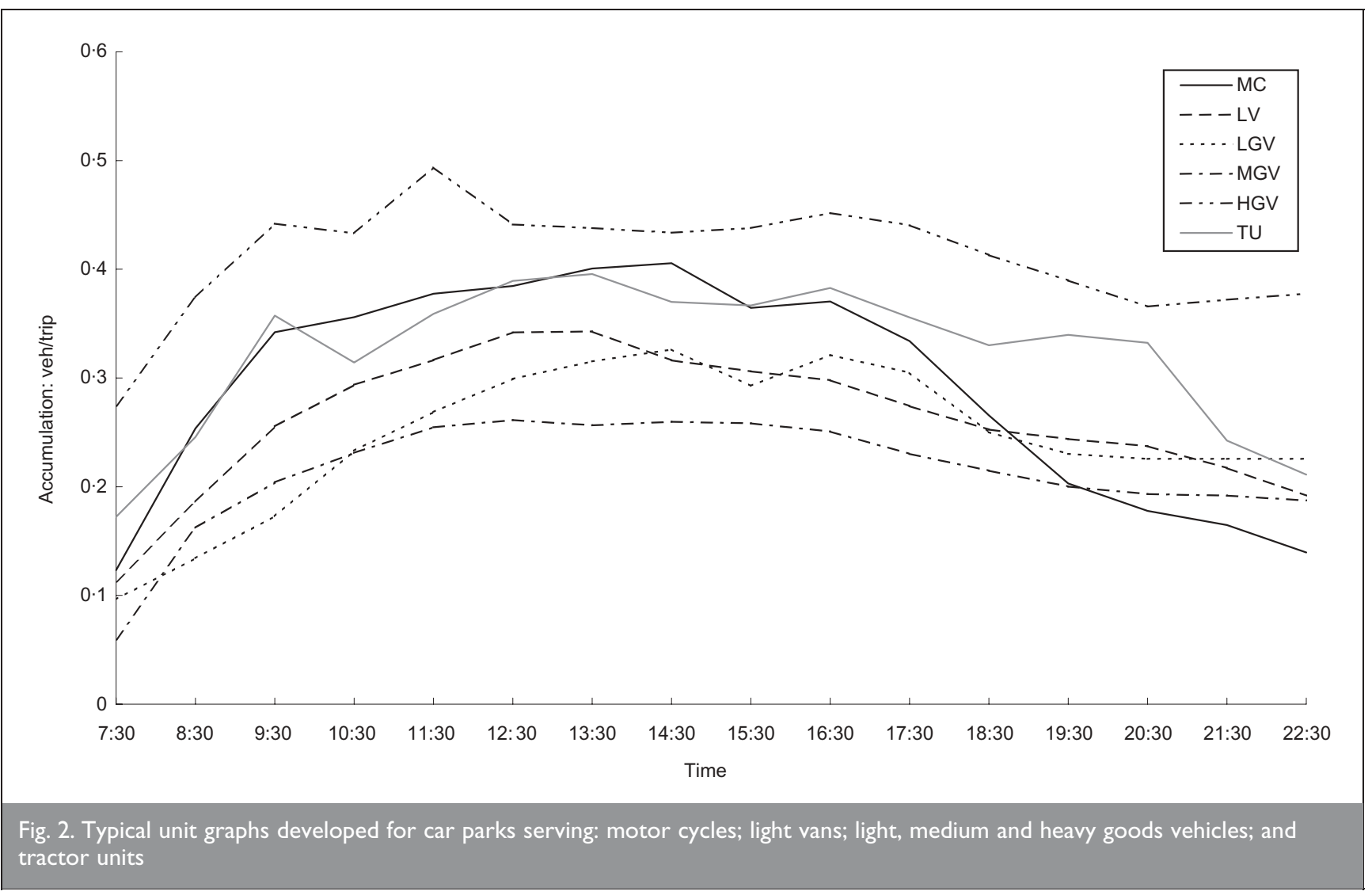




\begin{tabular}{|c|c|c|c|c|}
\hline $\begin{array}{l}\text { Destination land } \\
\text { use }\end{array}$ & $\begin{array}{c}\text { Search/wait time: } \\
\text { min }\end{array}$ & $\begin{array}{l}\text { Walk time: } \\
\text { min }\end{array}$ & $\begin{array}{l}\text { Parking fee: } \\
\$ \$ / \mathrm{h}\end{array}$ & $\begin{array}{l}\text { Sample } \\
\text { size }\end{array}$ \\
\hline Shopping & $3 \cdot 1$ & $3 \cdot 3$ & I & 150 \\
\hline Industrial & $2 \cdot 7$ & $2 \cdot 9$ & I & 81 \\
\hline Residential & $2 \cdot 0$ & $3 \cdot 4$ & I & 126 \\
\hline Office & $2 \cdot 1$ & $2 \cdot 9$ & I & 102 \\
\hline Recreation & 1.6 & 3.0 & I & 78 \\
\hline
\end{tabular}

Table I. Coefficients of different attributes affecting car park choice as perceived by private car users

\begin{tabular}{|c|c|c|c|c|}
\hline Vehicle type & $\begin{array}{l}\text { Search/wait time: } \\
\text { min }\end{array}$ & $\begin{array}{l}\text { Walk time: } \\
\text { min }\end{array}$ & $\begin{array}{l}\text { Parking fee: } \\
\qquad / \mathrm{h}\end{array}$ & $\begin{array}{l}\text { Sample } \\
\text { size }\end{array}$ \\
\hline Private car & $2 \cdot 3$ & $3 \cdot 1$ & I & 537 \\
\hline Light goods vehicles & $2 \cdot 7$ & 5.9 & i & 484 \\
\hline $\begin{array}{l}\text { Medium/heavy goods } \\
\text { vehicles }\end{array}$ & 1.8 & 3.9 & I & 349 \\
\hline
\end{tabular}

In order to model the location of trip ends more accurately, the 338 zone system trip matrices were further disaggregated into a more refined Base District Traffic Model (BDTM) system with 2140 zones. As individual car parks were geo-coded, their precise locations are known.

The allocation of parking trip ends to parking spaces is analogous to user optimal trip assignment. First, a network was constructed to link the attraction trip ends with admissible parking facilities. The criteria for admissibility were based on comparing the activity type (for private cars) or vehicle

choice. The coefficients obtained for private car users for different land uses are shown in Table 1. For goods vehicles, the dataset obtained was sufficient only to estimate the aggregate coefficients without differentiating between different land uses. These are shown in Table 2, together with the aggregate private car owner coefficients for comparison purposes. The results indicated that, for all vehicle users, walking time is considered more important than search/wait time.

In the same survey, respondents were also asked to provide information on their location of night-time parking, which was used for the development of the night-time parking demand model.

\section{DAYTIME PARKING DEMAND MODEL}

The objective of developing this model is to predict the future parking accumulation at different districts for the following vehicle classes:

(a) private cars, taxis and light vans

(b) light, medium and heavy goods vehicles

(c) tractors

(d) motor cycles.

The model was calibrated and validated for the base year 2000 and applied to the design years 2006 and 2011. It is a sub-model of another strategic transport model that provides generation/attraction trip matrices for travel by different modes for a 338 zoning system. ${ }^{7}$ The daytime activity trips were then segmented into parking and loading/unloading components and activity type, by a regression model based on the land use and parking supply characteristics of the attraction zone.

The model was developed at different levels of aggregation. First, for model calibration, the whole territory of Hong Kong was divided into 18 districts. Then it was subdivided into 35 sectors, with three focus sectors selected for model validation. type (for other vehicles) with the land use type (for private car spaces) or parking space type (for other vehicle type spaces). Then a parking choice model was established based on a generalised cost function with components consisting of parking search time, walking time and parking charge. The weightings attached to each component were obtained from the results of the stated preference survey described in section 6 . For the base year, the parking charges for different car parks were obtained during the parking characteristics survey. For the forecast year, the parking charges were supplied by the Planning Department. To account for capacity constraint, the method of successive averages was used to determine the user equilibrium solution. Thus in a zone in which parking demand exceeds supply, drivers are faced with various tradeoffs:

(a) park in a more expensive car park

(b) wait in a queue

(c) park in a less convenient location

requiring a longer walking distance. As all car park locations have been geo-coded, the parking choices are not constrained by zone boundaries. It is permissible for a trip destined to one zone to be parked in neighboring zones. Therefore, from the model outputs, two indices can be derived: (a) the selfcontainment ratio, which is defined as the percentage of trips destined to a zone that parks in the same zone; and (b) the average walking distance of drivers of vehicle trips destined to a zone. These two indices are indicators of the level of parking service provided at different locations of the city, which can be used for assessing the need for future improvements in parking services in various zones and districts.

Table 3 shows the observed and modelled peak accumulations for the year 2000 for different vehicles in different districts.

\section{NIGHT-TIME PARKING DEMAND MODEL}

From the night-time parking survey results, it is found that the vehicles can be classified into two groups according to their choice of parking locations. The first group consists of 


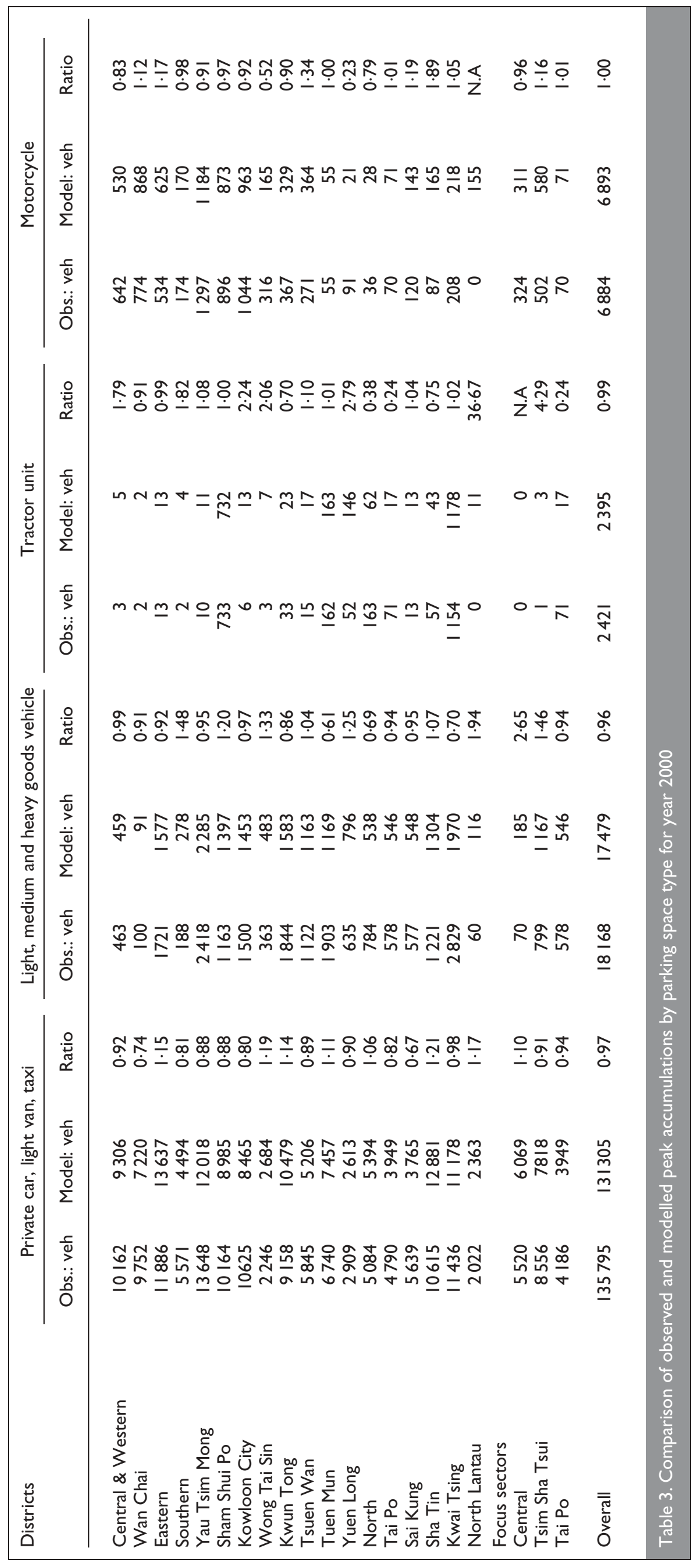


Private cars

Intra-district proportion

Motorcycles

93\%

$92 \%$

$70 \%$

Taxis

$82 \%$

Light goods vehicles

$79 \%$

The intra-district proportion is defined as the proportion of vehicles in which the night-time parking location is in the same district as the vehicle registration address location.

The other group of vehicles consists of

\begin{tabular}{lc} 
Medium goods vehicles & proportion \\
Heavy goods vehicles & $61 \%$ \\
Tractor units & $54 \%$ \\
Coaches and private light buses & $45 \%$ \\
Public light buses & $33 \%$ \\
\hline
\end{tabular}

For the first group of vehicles, it is considered that the vehicle registration addresses provide a sufficiently good estimate of their night-time parking locations. Using the base year overnight parking accumulation data, a zonal regression model was developed to relate the overnight parking accumulation of different vehicle types in a zone with the socio-economic and land use variables of that zone.

For the second group of vehicles, it would be more accurate to use the overnight parking survey data to project the base year night-time parking accumulation. As a result, a district-based regression model was developed for this group of vehicles.

\section{ASSESSMENT OF BASE YEAR AND FUTURE PARKING SITUATIONS}

The parking demand models developed for the study provided the computational tool for assessing base year and future parking situations. The assessment covered all major vehicle types for both daytime and night-time parking. Daytime parking refers to the need for drivers to park their cars at the place they want to visit, and is associated with the non-home end of the trip. This assessment identifies the surplus/shortfall of base year/future parking service provisions in different districts, and provides input to the review of planning standards governing parking service provisions in new developments.

The results of the assessment show that although the planning standards introduced in accordance with the recommendations given in PDS-1 are able to ensure a global balance in the supply and demand of parking services for private cars, there are still shortages in parking supply in some districts or zones, and flexibility should be introduced into the planning standards to ensure a closer match between supply and demand in different locations. Furthermore, there were general shortfalls of night-time parking spaces for goods vehicles, coaches and motorcycles in the base year, and this condition is likely to persist in the future unless some remedial actions are taken.

\section{I0. REVIEW OF PLANNING STANDARDS AND GUIDELINES}

The standards and guidelines relating to parking provision in various land use developments are specified in a government manual known as the Hong Kong Planning Standards and Guidelines (HKPSG). This manual is applied in planning studies, preparation/revision of town plans, and development control. It is also a document used as a tool to implement government policy and achieve policy objectives. PDS-2 reviewed the appropriateness and adequacy of existing parking standards specified in this manual for various land uses. A wide-ranging consultation with major stakeholders was also undertaken.

After the review, the study recommended revisions to the planning standards. The proposed revisions encompass a fundamental change to the establishment of parking standards using new criteria, particularly for private car parking in residential developments, in which the parking standard is based not on development density, but on a global standard of one parking space per six to nine flats. This global standard is flexible, and will be suitably adjusted by the planning authorities for individual developments, taking into account the public/private sector of housing, size of the flats and the accessibility of the development to rail stations. For industrial developments, the standards were also revised taking into account new types of development, in which industrial and business-type developments are integrated within the same building.

\section{I. RECOMMENDATIONS}

Various remedial measures that can be classified into three broad categories are recommended.

\section{I.I. Measures to be implemented through the planning} process

(a) Introduction of flexibility in the planning standards governing parking provision.

(b) Provision of park and ride and kiss and ride facilities at rail stations and transport interchanges so as to reduce the daytime private car parking demand in the urban areas.

(c) Introduction of land sales incentives to encourage private sector participation in the provision of multi-storey vehicle parks in new developments, which can effectively address parking space shortages, particularly for goods vehicles.

(d) Provision of goods vehicle/coach parking facilities in container backup areas.

(e) Formation of bicycle parking guidelines; for example, requiring provision of bicycle parking spaces at the vicinity of rail stations.

( f) Allowing flexible and integrated design for motorcycle parking. The introduction of metered on-street motorcycle spaces was considered, but was not implemented because the payment technology for such a system was not available.

\section{I.2. Measures to be implemented through} management

(a) Use of short-term tenancy sites (sites that are temporarily vacant) for parking. Although this is a short-term/interim measure, it is a quick and cost-effective solution in addressing parking space shortage for goods vehicles, 
especially container vehicles. Streamlining the procedure for application for temporary use of vacant sites for such purposes is recommended.

(b) Use of off-street goods vehicle loading/unloading spaces for night-time goods vehicle/coach parking.

(c) Use of daytime parking facilities in government buildings for public parking after office hours.

(d) Use of open spaces at government premises for goods vehicle/coach parking after office hours.

(e) Extending/regularising more nighttime on-street parking for goods vehicles and coaches.

$(f)$ Converting on-street private car parking spaces for coach/ taxi parking or loading/unloading.

(g) Provision of 'No Waiting' kerbside loading/unloading areas for coaches and taxis.

\section{I.3. Measures to be implemented by using advanced technology}

(a) Use of mechanical parking systems to increase the capacity of car parks.

(b) Use of parking guidance systems to optimise car park usage.

(c) Provision of parking information systems to disseminate real-time or near-real-time information to drivers.

\section{CONCLUSIONS}

This paper has briefly described the background, objectives, surveys, demand models, findings and recommendations of the Hong Kong Second Parking Demand Study. As this is a study with a wide scope, it is not possible to provide all the details in this paper. More detailed information about this study can be found in reference 4 .

\section{ACKNOWLEDGEMENTS}

The Transport Department of the Hong Kong Special Administrative Region is gratefully acknowledged for giving permission to publish this paper, which is based on work that was carried out during the Second Parking Demand Study. The views that are expressed in this paper are the responsibility of the authors, and do not necessarily represent those of the Government of the Hong Kong Special Administrative Region. The research was partially supported by the Industry Fellow and Industry Associate Schemes and the Faculty Innovative and Technology Fund of the University of Hong Kong (Project Account: 10300172). The authors wish to thank Dr Y. L. Choi, Senior Industry Fellow of the University of Hong Kong, for his helpful suggestions and useful comments on an earlier version of the paper.

\section{REFERENCES}

1. Tong C. O. and Wong S. C. The advantages of a high density, mixed land use, linear urban development. Transportation, 1997, 24, 295-307.

2. Thompson D., EAglestone A., Tong C. O. and Wong S. C. Development of a sub-regional forecasting model for the Comprehensive Traffic Review of East Kowloon, Hong Kong. Proceedings of the Institution of Civil Engineers-Transport, 2000, 141, No. 2, 87-97.

3. LAM W. C. H., Fung R. Y. C., Wong S. C. and Tong C. O. The Hong Kong parking demand study. Proceedings of the Institution of Civil Engineers-Transport, 1998, 129, No. 4, 218-227.

4. Ove Arup \& Partners Hong Kong Ltd. The Second Parking Demand Study, Technical Report. Prepared for Transport Department, Hong Kong Special Administrative Region, 2002.

5. Wong S. C., Tong C. O., LAM C. H. and Fung Y. C. Development of parking demand models in Hong Kong. ASCE Journal of Urban Planning and Development, 2000, 126, No. 2, 55-74.

6. TonG C. O., Wong S. C. and LeUnG B. S. Y. Estimation of parking accumulation profiles from survey data. Transportation, 2004, 31, 183-202.

7. TRANSPORT DePartment AND Wilbur SMith AND AsSOCiates. Third Comprehensive Transport Study: Final Report. Hong Kong Special Administrative Region, 1999.

Please email, fax or post your discussion contributions to the secretary by I August 2005: email: journals@ice.org.uk; fax: +44 (0)20 665 2294; or post to Journals Department, Institution of Civil Engineers, I-7 Great George Street, London SWIP 3AA. 